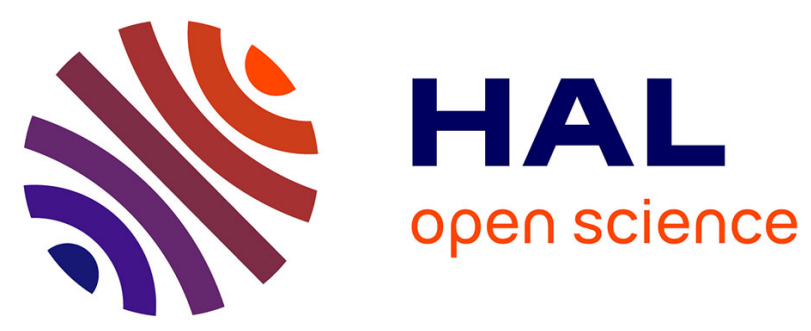

\title{
Overall, specific, and metastasis-free survival of Afro-Caribbean men with pathological Gleason 6 prostate cancer
}

Philippe Mollard, Emmanuel Perrot, Pascal Blanchet, Laurent Brureau

\section{- To cite this version:}

Philippe Mollard, Emmanuel Perrot, Pascal Blanchet, Laurent Brureau. Overall, specific, and metastasis-free survival of Afro-Caribbean men with pathological Gleason 6 prostate cancer. Prostate, 2020, 80 (4), pp.329-335. 10.1002/pros.23947 . hal-02434534

HAL Id: hal-02434534

https://hal-univ-rennes1.archives-ouvertes.fr/hal-02434534

Submitted on 17 Feb 2020

HAL is a multi-disciplinary open access archive for the deposit and dissemination of scientific research documents, whether they are published or not. The documents may come from teaching and research institutions in France or abroad, or from public or private research centers.
L'archive ouverte pluridisciplinaire HAL, est destinée au dépôt et à la diffusion de documents scientifiques de niveau recherche, publiés ou non, émanant des établissements d'enseignement et de recherche français ou étrangers, des laboratoires publics ou privés. 
Title: Overall, specific, and metastasis-free survival of Afro-Caribbean men with pathological Gleason 6 prostate cancer.

\title{
Running title: Survival of men with pathological Gleason 6 prostate cancer
}

\author{
Philippe MOLLARD M.D. ${ }^{1}$, Emmanuel PERROT M.D. ${ }^{1}$, Pascal BLANCHET M.D., Ph.D. ${ }^{2}$, \\ and Laurent BRUREAU M.D, Ph.D. ${ }^{2 *}$
}

\begin{abstract}
${ }^{1}$ CHU de Pointe-à-Pitre, Service d’Urologie, 97159 Pointe-à-Pitre Cedex ${ }^{2}$ CHU de Pointe-à-Pitre, Univ Antilles, Univ Rennes, Inserm, EHESP, Irset (Institut de Recherche en Santé, Environnement et Travail) - UMR_S 1085, F-97110 Pointe-à-Pitre, France
\end{abstract}

*Correspondence should be addressed to Laurent Brureau

Urology department, University Hospital of Pointe-à-Pitre, F-97159 Pointe-à-Pitre, Tel : +590690701517.

Fax : +590 590891787

Email : brureau_laurent@yahoo.fr 


\section{Abstract \\ Background}

Several studies in the Caucasian population have shown that patients with Gleason 6 prostate cancer, based on surgical specimens, have low or no risk of metastasis. However, there is no data for men of African ancestry. The objective of this study was to estimate the overall, specific, and metastasis-free survival of patients with a Gleason 6 score, based on the surgical specimen.

\section{Patients and methods}

This was a monocentric retrospective study that included 723 consecutive patients treated by radical prostatectomy between January 1, 2000 and March 31, 2018, with a Gleason score of 6 based on the surgical specimen. Specific survival was defined as the time elapsed between surgery and death attributed to prostate cancer. Overall survival was defined as the time elapsed between surgery and death from all causes. The causes of death were verified in the medical records.

Survival analyses without biochemical recurrence and without salvage treatment were performed according to the Kaplan-Meier method. The Cox model was used for univariate and multivariate analyses.

\section{Results}

In total, 691 patients were included because 32 were excluded for missing data. Overall five- and ten-year survival were $94.2 \%$ and $87.1 \%$, respectively. Specific survival and metastasis-free survival were $100 \%$, with a median follow-up of 8.5 years. The biochemical recurrence rate was $16.5 \%$, with a median time to biochemical recurrence of 5.1 years. The frequency of salvage treatment was $13.0 \%$, with a median time to surgery of 7.3 years. In univariate analysis, PSA, pathological stage, seminal vesicle invasion, positive margins, and lymph node dissection were significantly associated with an increased risk of biochemical 
recurrence and salvage treatment, but only PSA and positive margins were significantly associated by multivariate analysis.

\section{Discussion / Conclusion:}

No metastasis or disease-specific deaths were observed for men with Gleason score $\leq 6$ prostate cancer at radical prostatectomy, in particular, men of African ancestry.

Key words: prostate cancer, radical prostatectomy, Gleason score, survival, metastasis 


\section{Introduction}

Prostate cancer is the second most common malignancy in men worldwide, accounting for 1,276,106 new cases and causing 358,989 deaths in 2018 [1]. Some have suggested that patients with Gleason 6 prostate cancer have a low potential to become metastatic [2]. Several studies on the Caucasian population have been performed and reported a lower rate of recurrence, lymph node invasion, and metastatic disease in men with Gleason 6 prostate cancer than those with a higher Gleason score [3-7].

Populations of African ancestry display more aggressive disease and a higher worldwide mortality rate from prostate cancer than other ethnic populations [8, 9]. The reasons for such ethnicity-based differences in incidence are largely unknown, but probably involve a complex interplay between hormonal, environmental, and genetic factors [10]. In 2018, Mahal et al. reported on their analysis of a database of 403,022 men with localized prostate cancer, showing that black men with Gleason 6 prostate cancer were twice as likely to die than the rest of the sample [11].

Our objective was to estimate overall, specific, and metastasis-free survival in an AfroCaribbean cohort of patients with pathological Gleason 6 prostate cancer.

\section{Patients and Methods}

\section{Study population}

This was a retrospective study of prostate-cancer patients undergoing radical prostatectomy (RP) at the University Hospital of Guadeloupe, corresponding to approximately $60 \%$ new cases. Guadeloupe is a French-Caribbean archipelago of 410,000 inhabitants where most of the population ( $\sim 90 \%$ ) is of African ancestry. From our cohort of 2,254 men who underwent RP, 723 patients were included between January 1, 2000 and March 31, 2018, of whom 32 
were excluded due to missing data. No patients received neoadjuvant hormonal therapy or radiotherapy. Only men classified as having pathological Gleason $6(3+3)$ prostate cancer after RP were considered. Before 2005, Gleason grading was applied, whereas afterwards, modified Gleason grading was used, according to the major changes in Gleason grading in 2005 and 2014 [12-14]. All specimens were reviewed by a pathologist of our institution. However, several cases were sent to an expert center for analysis when there was doubt. After surgery, all patients were followed by serial PSA determinations and clinical visits every six months for the first three years and annually thereafter. Biochemical recurrence (BCR) was defined as two consecutive (usually four weeks apart) PSA measurements above $0.2 \mathrm{ng} / \mathrm{ml}$. Metastasis was defined as the presence of prostate cancer in a lymph node or at a distant site with radiological or pathological confirmation.

\section{Data collection}

For each patient, we collected data on their age at positive biopsy and surgery, the preoperative PSA value, clinical stage, biopsy Gleason score, date of surgery, type of surgery, perioperative blood loss (as recorded in the operative notes), pathological stage, pathological Gleason score, surgical margins, lymphadenectomy status, prostate weight, follow-up PSA, status of dead or living, and cause of death.

Only the medical data from the database of all RPs performed in our department were used. The study was approved by the Ethics Committee of the University Hospital of Guadeloupe.

\section{Statistical analysis}

Outcome variables were BCR, defined as the time from RP to BCR; metastasis-free survival (MFS), defined as the time from RP to metastasis (lymph node, distant metastasis, or both); specific survival (SS), defined as the time from RP to death attributed to prostate cancer; and 
overall survival (OS), defined as the time from RP to all-cause death. Death and diseasespecific death were identified during the review of the medical records.

Survival probabilities were estimated by the Kaplan-Meier method. The hazard ratio (HR) and 95\% confidence intervals (CI) for the association between individual characteristics and BCR were estimated using the Cox proportional-hazards regression model for univariate and multivariate analyses. Only significant variables in the univariate model were included in multivariate model. Time to event was defined as the duration between the date of surgery and the PSA value that defined the recurrence event. Patients who did not relapse were censored at the last normal post-operative PSA measurement, before March 31, 2018.

The survival rate without salvage treatment was calculated using the Kaplan-Meier method. Time to salvage treatment was defined as the duration between the date of surgery and the date of the beginning of salvage treatment. Univariate and multivariate analyses for salvage treatment were performed as for BCR.

All tests were two-tailed, and P values $<0.05$ were considered to be statistically significant.

All analyses were carried out using StatView version 5.0 and MedCalc version 17.5 software.

\section{Results}

In total, 691 patients were included in the present study. The median age at the time of surgery was 64.1 years (45.3 - 76.8). The median PSA concentration at diagnosis was 6.8 $\mathrm{ng} / \mathrm{ml}(1.0-53.2)$. Almost all $(89.6 \%)$ patients had a Gleason score $\leq 6$ on biopsy. The baseline characteristics of all patients are summarized in Table 1. A total of 114 patients (16.5\%) had BCR with a median time to event of 5.1 years. Ninety men (13\%) received salvage treatment with a median time to surgery of 7.3 years. Five- and ten-year OS was 
$94.2 \%$ and $87.1 \%$, respectively. The status of being dead or alive could not be confirmed for 39 patients. However, at the date of the latest news, these patients had low PSA levels, no systemic treatment, and no evidence of local or distant recurrence. The SS and MFS were $100 \%$ at five and ten years, with a median duration of follow-up of 8.5 years.

In the survival analysis, there was a significant difference between pT2 and pT3 pathological stage for five- $(\mathrm{HR}=2.11 ; 95 \% \mathrm{CI}[1.01-4.41], \mathrm{p}=0.008)$ and ten-year BCR-free survival $(\mathrm{HR}=2.29,95 \% \mathrm{CI}[1.22-4.29], \mathrm{p}=0.0004)$. There was also a significant difference between positive margins or not for five- (HR = 3.26 ; 95\% CI $[1.87-5.69], \mathrm{p}<0.0001)$ and ten-year BCR-free survival $(\mathrm{HR}=2.74,95 \%$ CI $[1.68-4.46], \mathrm{p}=0.0001)$. All data for significant BCR-free survival are summarized in Figure 1. We obtained similar results for time to salvage treatment-free survival (summarized in Figure 2).

In univariate analysis, predictive factors associated with BCR were PSA, pathological stage (pT3), seminal vesicle invasion (pT3b), positive surgical margins, and lymphadenectomy (Table 2). High PSA $(p<0.005)$ and positive margins $(p=0.01)$ were factors for BCR in multivariate analysis (Table 3). The results were similar for uni- and multivariate analysis for salvage treatment (summarized in Tables 4 and 5).

\section{Discussion}

This is the first study to investigate MFS, SS, and OS for men with Gleason 6 prostate cancer based on RP specimens in an Afro-Caribbean population. The strengths of our study include the small amount of missing data, the number of patients included, and the median follow-up of 8.5 years. This population is known to have one of the highest incidences of prostate cancer in the world and more aggressive disease, with a higher Gleason score than Caucasian men [15]. We show a negligible potential for prostate cancer metastasis and death for men with 
Gleason $\leq 6$ prostate cancer treated by RP. Previous studies have reported similar results in the Caucasian population. No metastasis or disease-specific deaths were observed for men with pathological Gleason $\leq 6$ with similar baseline characteristics: for example, median age of 64 years, PSA at diagnosis of $6.2 \mathrm{ng} / \mathrm{ml}$, extracapsular extension in $17 \%$ of cases, invasion of seminal vesicles in $0.4 \%$ of cases, and $20 \%$ with a positive surgical margin $[7,16]$.

Unlike many tumors, prostate cancer is a heterogeneous disease and susceptible to sampling error. The average rate of upgrading between biopsy Gleason score and surgical specimen Gleason score is approximately 30\%. This finding does not allow extrapolation of survival data based on the pathological Gleason score of 6 to the Gleason score of 6 based on biopsies. Epstein et al. showed that $20 \%$ of the surgical specimens from a cohort of 7,643 prostatectomies had a tertiary grade pattern. Of the 5,071 cases of Gleason 5-6 at biopsy, only 63.7\% were Gleason 5-6 after RP and 11.2\% Gleason 6 with tertiary grade, the remainder (25.1\%) being classified Gleason $\geq 7$. Finally, $12.4 \%$ and $3.6 \%$ of cases had a Gleason score at biopsy of $7(3+4)$ and $7(4+3)$, respectively, with a Gleason 6 plus tertiary at RP [17]. Furthermore, in our present study, $7.2 \%$ of Gleason 6 prostate cancer had extra prostatic expansion (pT3a) and 2.7\% seminal vesicle involvement, indicating that these tumors can show locally aggressive behavior.

Limitations of our study were its retrospective nature and the absence of the review of cases after modification of the grading score system. However, the modifications of the Gleason score only led to the reclassification of grade 3 to grade 4 . The grading system was reviewed by the International Society of Urological Pathology (ISUP) at the 2005 consensus conference. In the modified criteria, poorly defined glands with poorly formed glandular lumina, large cribriform glands with smooth edges, and the glomeruloid glands classically described as grade 3 adenocarcinoma were redefined as grade 4 [18], whereas the last ISUP consensus conference in 2014 redefined the Gleason score into five prognostic groups [19]. In 
our study, two patients with metastasis were classified as Gleason 7 after review and were excluded. In 2012, Dong et al. reviewed the specimens of 806 patients treated by RP with Gleason 6 and Gleason 7 scores $(3+4)$, according to the modified grading system. The review of Gleason 6 specimens led to upgrading to Gleason 7 for 34\% according to modified ISUP criteria. In contrast, no case of Gleason $7(3+4)$ was reclassified as Gleason 6 [20].

One of the main challenges over the next few years will be to unambiguously detect men with Gleason 6 prostate cancer, without upgrading based on surgical specimens. This will probably occur due to improved imaging techniques, better knowledge of molecular biology, and the development of artificial intelligence.

\section{Conclusion}

In conclusion, no metastasis or disease-specific deaths were observed for men with Gleason score $\leq 6$ prostate cancer at RP, in particular, that of men of African ancestry.

Words account: 1657 
Acknowledgement

There is no particular acknowledgement for this work. 


\section{Conflict of interest}

The authors declare that they have no conflict of interest. 


\section{References}

1. Bray F, Ferlay J, Soerjomataram I, Siegel RL, Torre LA, Jemal A. Global cancer statistics 2018: GLOBOCAN estimates of incidence and mortality worldwide for 36 cancers in 185 countries. CA Cancer J Clin. 2018; 68(6):394-424.

2. Ahmed HU, Arya M, Freeman A, Emberton M. Do low-grade and low-volume prostate cancers bear the hallmarks of malignancy? The Lancet Oncol 2012; 13:e50917.

3. Donin NM, Laze J, Zhou M, Ren Q, Lepor H. Gleason 6 prostate tumors diagnosed in the PSA era do not demonstrate the capacity for metastatic spread at the time of radical prostatectomy. Urology 2013; 82:148-52.

4. Miyamoto, H, Hernandez, DJ, Epstein, JI. A pathological reassessment of organconfined, Gleason score 6 prostatic adenocarcinomas that progress after radical prostatectomy. Hum Pathol 2009; 40: 1693- 1698.

5. Wenger H, Weiner AB, Razmaria A, Paner GP, Eggener SE. Risk of lymph node metastases in pathological Gleason score $<=6$ prostate adenocarcinoma: analysis of institutional and population-based databases. Urol Oncol. 2017;35(1):31.e1-31.e6.

6. Ross HM, Kryvenko ON, Cowan JE, Simko JP, Wheeler TM, Epstein JI. Do adenocarcinomas of the prostate with Gleason score (GS) r6 have the potential to metastasize to lymph nodes? Am J Surg Pathol 2012; 36:1346-52.

7. Kweldam CF, Wildhagen MF, Bangma CH, van Leenders GJ. Disease-specific death and metastasis do not occur in patients with Gleason score $r 6$ at radical prostatectomy. BJU Int 2015; 116:230-5.

8. Deloumeaux J, Bhakkan B, Eyraud R, Braud F, Manip M’Ebobisse N, Blanchet P, et al. Prostate cancer clinical presentation, incidence, mortality and survival in Guadeloupe over the period 2008-2013 from a population-based cancer registry. Cancer Causes Control CCC. 2017; 28(11):1265-1273.

9. Ben-Shlomo Y, Evans S, Ibrahim F, Patel B, Anson K, Chinegwundoh F, et al. The risk of prostate cancer amongst black men in the United Kingdom: the PROCESS cohort study. Eur Urol. 2008; 53(1):99-105.

10. Rebbeck TR. Prostate Cancer Genetics: Variation by Race, Ethnicity, and Geography. Semin Radiat Oncol. 2017; 27(1):3-10.

11. Mahal BA, Berman RA, Taplin ME, Huang FW. Prostate cancer-specific mortality across Gleason scores in black vs nonblack men. JAMA. 2018; 320(23):2479-2481.

12. Gleason DF, Mellinger GT. Prediction of prognosis for prostatic adenocarcinoma by combined histological grading and clinical staging. J Urol. 1974;111:58-64. 
13. Epstein JI, Allsbrook WC, Jr, Amin MB, Egevad LL ISUP Grading Committee. The 2005 International Society of Urological Pathology (ISUP) consensus conference on Gleason grading of prostatic carcinoma. Am J Surg Pathol. 2005; 29:1228-42.

14. Epstein JI, Egevad L, Amin MB, Delahunt B, Srigley JR, Humphrey PA, et al. The 2014 international society of urological pathology (ISUP) consensus conference on Gleason grading of prostatic carcinoma: Definition of grading patterns and proposal for a new grading system. Am J Surg Pathol. 2016; 40:244-52.

15. Fowler JE Jr, Bigler SA. Racial differences in prostate carcinogenesis. Histologic and clinical observations. Urol Clin North Am. 2002; 29(1):183-91.

16. Lepor H, Donin NM. Gleason 6 prostate cancer: serious malignancy or toothless lion? Oncology 2014; 28(1):16-22.

17. Epstein JI, Feng Z, Trock BJ, Pierorazio PM. Upgrading and downgrading of prostate cancer from biopsy to radical prostatectomy: incidence and predictive factors using the modified Gleason grading system and factoring in tertiary grades. Eur Urol. 2012; 61(5):1019-1024.

18. Epstein JI, Allsbrook WC, Jr., Amin MB, Egevad LL, Committee IG. The 2005 International Society of Urological Pathology (ISUP) Consensus Conference on Gleason Grading of Prostatic Carcinoma. Am J Surg Pathol 2005; 29:1228-42.

19. Epstein JI, Egevad L, Amin MB, Delahunt B, Srigley JR, Humphrey PA, et al. The 2014 International Society of Urological Pathology (ISUP) Consensus Conference on Gleason Grading of Prostatic Carcinoma: Definition of Grading Patterns and Proposal for a New Grading System. Am J Surg Pathol 2016; 40:244-52.

20. Dong F, Wang C, Farris AB et al. Impact on the clinical outcome of prostate cancer by the 2005 international society of urological pathology modified Gleason grading system. Am J Surg Pathol 2012; 36:838-43. 
Figure legends

Figure 1. Five- and ten-year BCR-free survival
a- Pathological stage (5 years)
b- Pathological stage (10 years)
c- Seminal vesicle invasion (5 years)
d- Seminal vesicle invasion (10 years)
e- Surgical margins (5 years)
f- Surgical margins (10 years)
g- Lymphadenectomy (5 years)
h- Lymphadenectomy (10 years)

Figure 2. Survival analysis for time to salvage treatment
a- Pathological stage
b- Seminal vesicle invasion
c- Surgical margins
d- Lymphadenectomy 

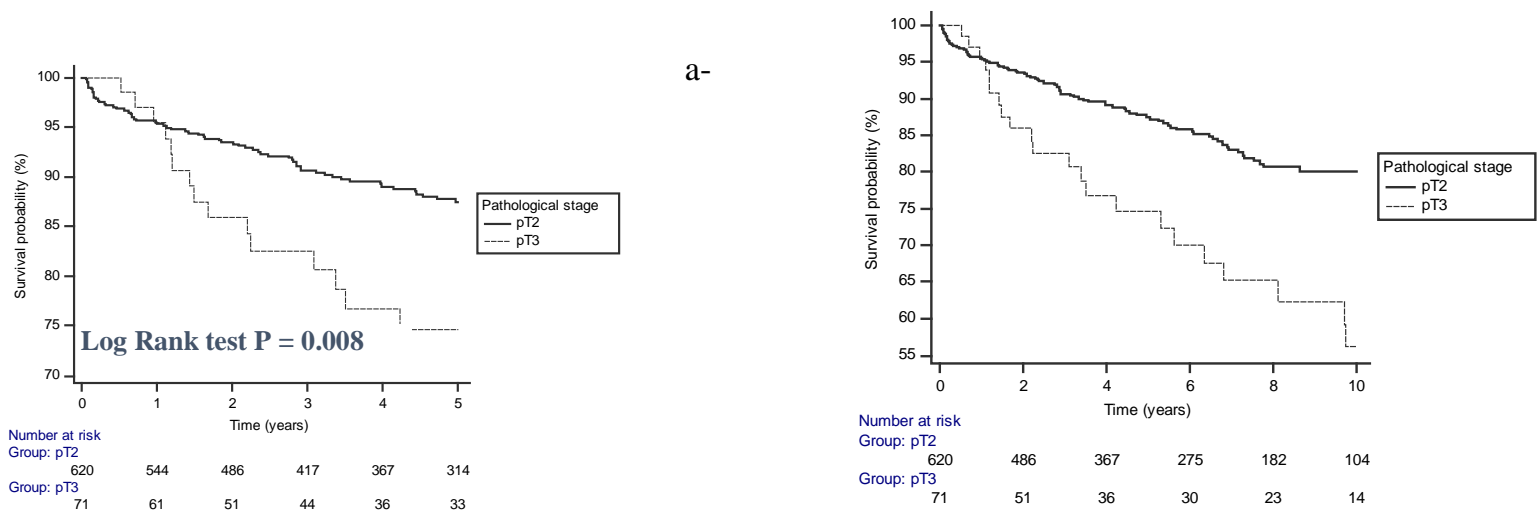

Pathological stage (5 years)

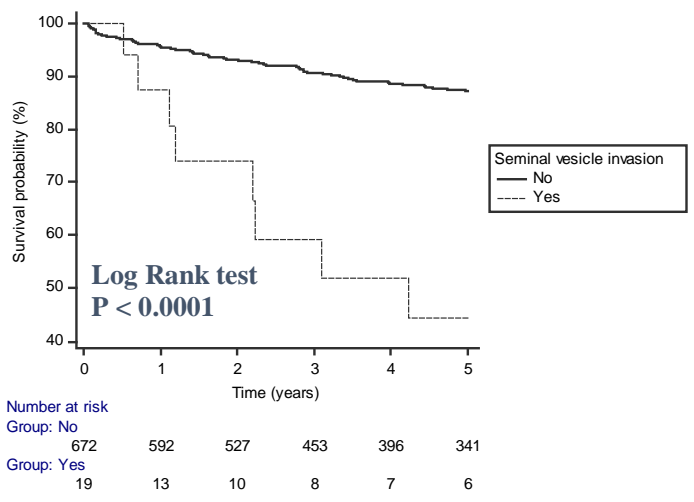

c- Seminal vesicle invasion (5 years)

e- Surgical margins (5 years)
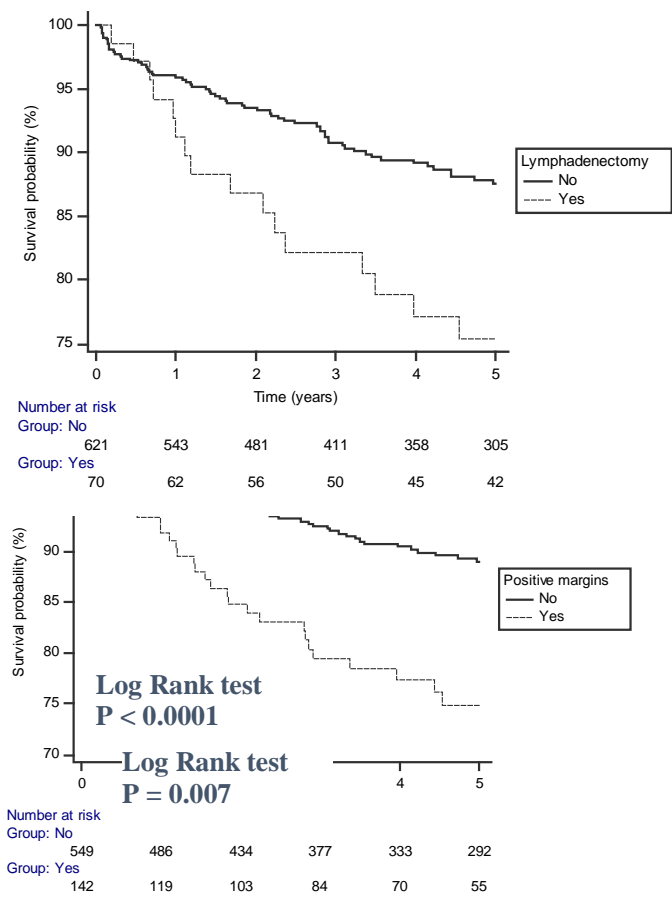

g-

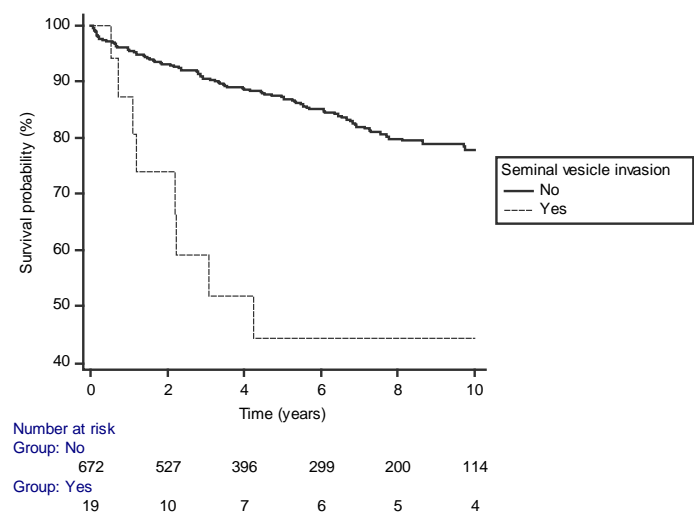

d- Seminal vesicle invasion (10 years)

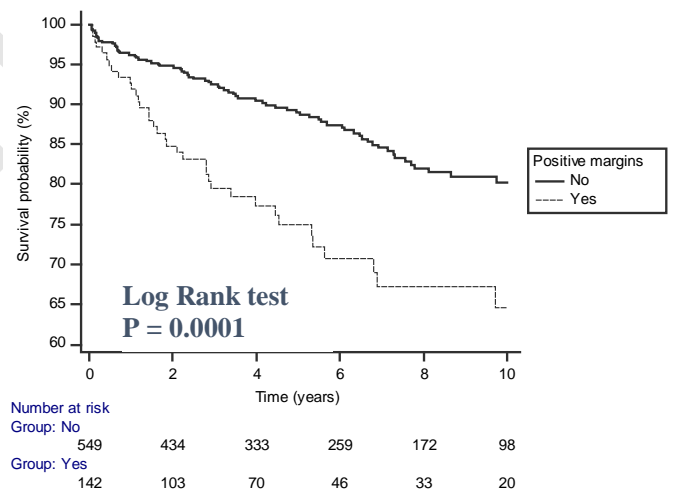

f- Surgical margins (10 years)

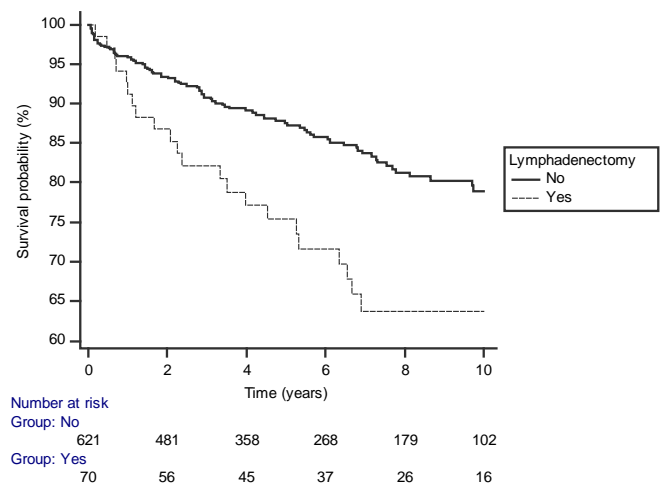

h- Lymphadenectomy (10 years)

Figure 1. Five- and ten-year BCR-free survival

b- Pathological stage (10 years) 


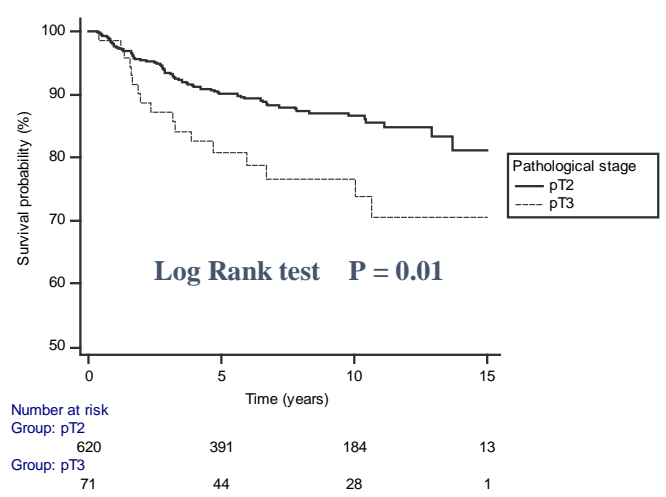

a-Pathological stage

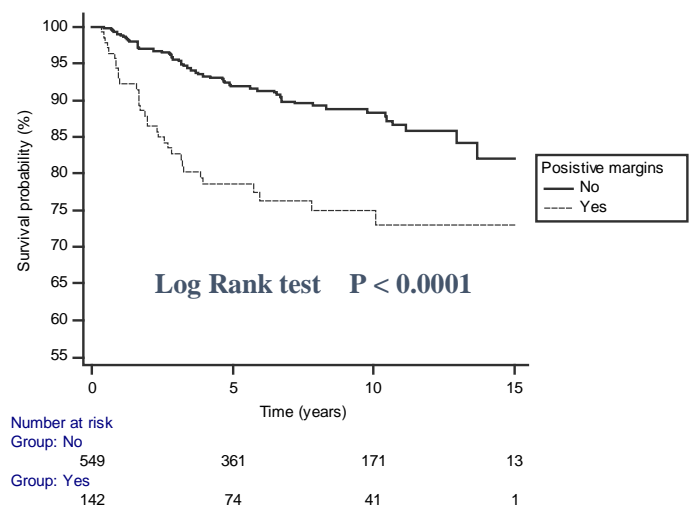

c- Surgical margins

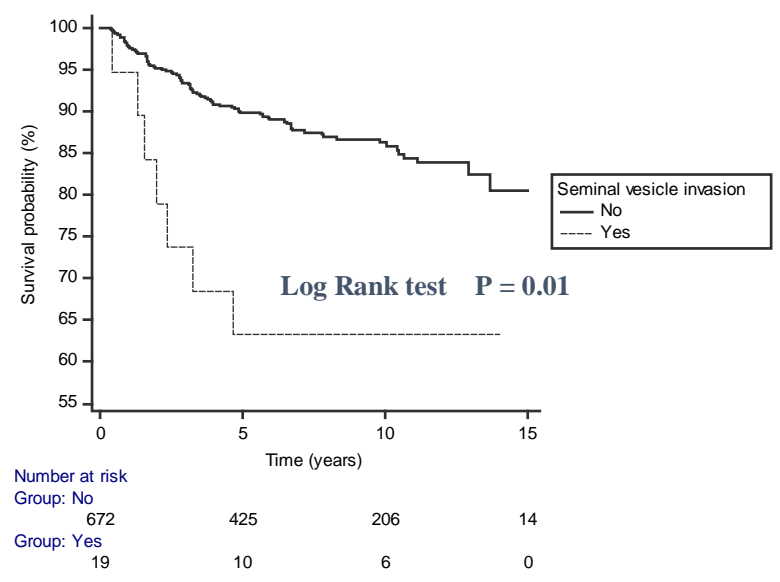

b- Seminal vesicle invasion

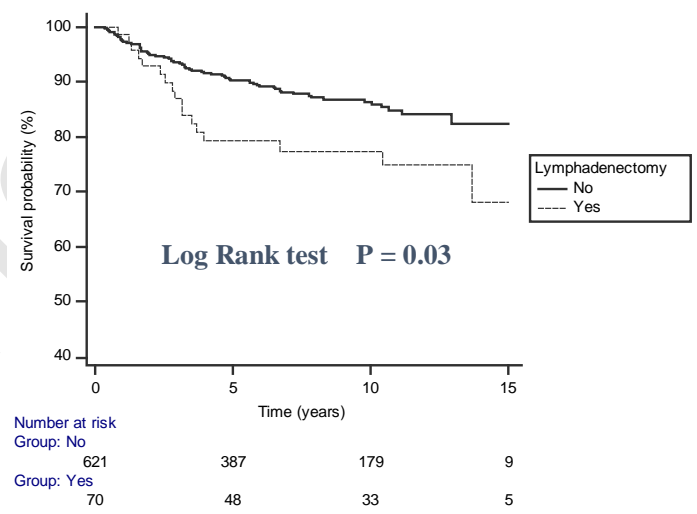

d- Lymphadenectomy

Figure 2. Survival analysis for time to salvage treatment 


\section{Tables and their legends}

Table 1. Baseline characteristics of all patients

Table 2. Univariate analyses of BCR risk factors

Table 3. Multivariate analyses of BCR risk factors

Table 4. Univariate analyses for predictive factors of salvage treatment

Table 5. Multivariate analyses for predictive factors of salvage treatment 
Table 1. Baseline characteristics of all patients

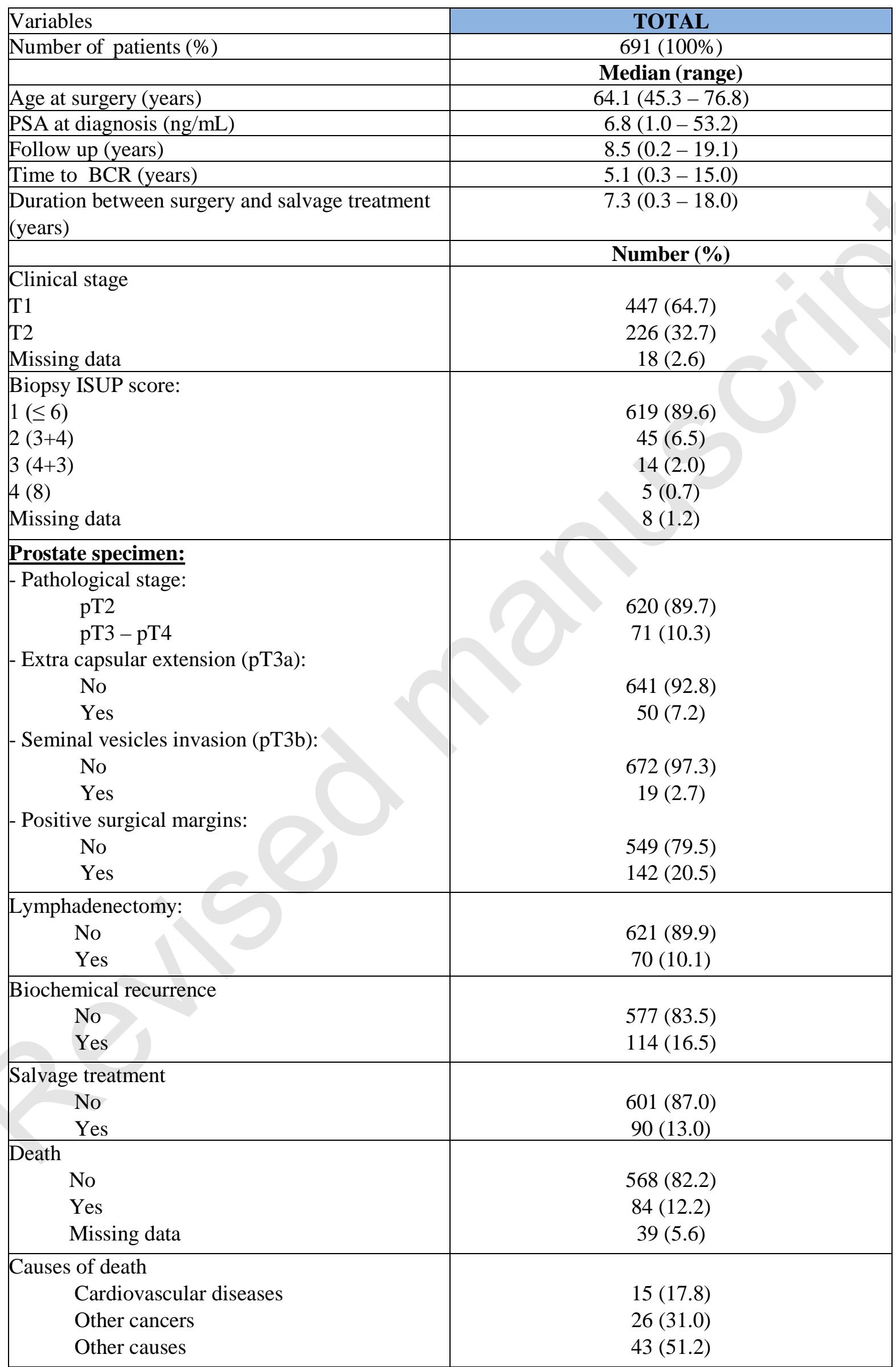


Table 2. Univariate analyses of BCR risk factors

\begin{tabular}{|c|c|c|c|}
\hline Variables & HR & $95 \%$ CI & $P$ value \\
\hline Age (years) & 1.00 & $0.98-1.03$ & 0.76 \\
\hline PSA (ng/ml) & 1.06 & $1.03-1.09$ & $<0.0001$ \\
\hline $\begin{array}{l}\text { Pathological stage } \\
\text { pT2 } \\
\text { pT3 }(a+b) \\
\end{array}$ & $\begin{array}{c}1.0 \\
2.24 \\
\end{array}$ & $\begin{array}{c}- \\
1.41-3.54 \\
\end{array}$ & $\begin{array}{c}- \\
0.0006 \\
\end{array}$ \\
\hline $\begin{array}{l}\text { Extracapsular Invasion } \\
\text { No } \\
\text { Yes }\end{array}$ & $\begin{array}{c}1.0 \\
1.63\end{array}$ & $\begin{array}{c}- \\
0.93-2.85 \\
\end{array}$ & 0.09 \\
\hline $\begin{array}{l}\text { Seminal vesicles invasion } \\
\text { No } \\
\text { Yes }\end{array}$ & $\begin{array}{c}1.0 \\
3.56 \\
\end{array}$ & $1.73-7.31$ & $\begin{array}{c}- \\
0.0006\end{array}$ \\
\hline $\begin{array}{l}\text { Positive margins } \\
\text { No } \\
\text { Yes }\end{array}$ & $\begin{array}{c}1.0 \\
2.18\end{array}$ & $\begin{array}{c}- \\
1.47-3.23\end{array}$ & $\begin{array}{c}- \\
0.0001\end{array}$ \\
\hline $\begin{array}{l}\text { Lymphadenectomy } \\
\text { No } \\
\text { Yes } \\
\end{array}$ & $\begin{array}{c}1.0 \\
2.00 \\
\end{array}$ & $\begin{array}{c}- \\
1.27-3.16 \\
\end{array}$ & $\begin{array}{c}- \\
0.003 \\
\end{array}$ \\
\hline
\end{tabular}


Table 3. Multivariate analyses of BCR risk factors

\begin{tabular}{|l|c|c|c|}
\hline Variables & HR & $\mathbf{9 5 \% ~ C I ~}$ & P value \\
\hline PSA (ng/ml) & $\mathbf{1 . 0 4}$ & $\mathbf{1 . 0 1}-\mathbf{1 . 0 8}$ & $<\mathbf{0 . 0 0 5}$ \\
\hline Pathological stage & & & \\
$\quad$ pT2 & 1.0 & - & - \\
pT3 (a+b) & 1.60 & $0.98-2.61$ & 0.059 \\
\hline $\begin{array}{l}\text { Positive margins } \\
\text { No }\end{array}$ & 1.0 & - & - \\
$\quad$ Yes & $\mathbf{1 . 7 3}$ & $\mathbf{1 . 1 4 - 2 . 6 4}$ & $\mathbf{0 . 0 1}$ \\
\hline Lymphadenectomy & & & \\
$\quad$ No & 1.0 & - & - \\
$\quad$ Yes & 1.40 & $0.86-2.29$ & 0.18 \\
\hline
\end{tabular}


Table 4. Univariate analyses for predictive factors of salvage treatment

\begin{tabular}{|l|c|c|c|}
\hline Variables & HR & 95\% CI & P value \\
\hline Age (years) & 1.00 & $0.97-1.04$ & 0.83 \\
\hline PSA (ng/ml) & $\mathbf{1 . 0 6}$ & $\mathbf{1 . 0 3 - 1 . 0 9}$ & $\mathbf{0 . 0 0 0 4}$ \\
\hline Pathological stage & & & \\
$\quad$ pT2 & 1.0 & - & - \\
pT3 (a+b) & $\mathbf{1 . 9 4}$ & $\mathbf{1 . 1 4 - 3 . 3 0}$ & $\mathbf{0 . 0 1 4}$ \\
\hline Extracapsular Invasion & & & \\
$\quad$ No & 1.0 & - & - \\
$\quad$ Yes & 1.26 & $0.63-2.51$ & 0.52 \\
\hline Seminal vesicles invasion & & & - \\
$\quad$ No & 1.0 & - & $\mathbf{0 . 0 0 2}$ \\
$\quad$ Yes & 3.38 & $\mathbf{1 . 5 6 - 7 . 3 1}$ & - \\
\hline Positive margins & 1.0 & - & $<$ \\
$\quad$ No & $\mathbf{2 . 5 4}$ & $\mathbf{1 . 6 5 - 3 . 9 0}$ & $\mathbf{0 . 0 0 0 1}$ \\
$\quad$ Yes & & & - \\
\hline Lymphadenectomy & 1.0 & - & $\mathbf{0 . 0 3 5}$ \\
$\quad$ No & $\mathbf{1 . 7 7}$ & $\mathbf{1 . 0 4}-\mathbf{3 . 0 3}$ & \\
Yes & & & \\
\hline
\end{tabular}


Table 5. Multivariate analyses for predictive factors of salvage treatment

\begin{tabular}{|l|c|c|c|}
\hline Variables & HR & $\mathbf{9 5 \%}$ CI & P value \\
\hline PSA (ng/ml) & $\mathbf{1 . 0 5}$ & $\mathbf{1 . 0 1} \mathbf{- 1 . 0 9}$ & $\mathbf{0 . 0 1 3}$ \\
\hline Pathological stage & & & \\
$\quad$ pT2 & 1.0 & - & - \\
pT3 (a+b) & 1.27 & $0.73-2.24$ & 0.40 \\
\hline Positive margins & & & \\
$\quad$ No & 1.0 & - & - \\
$\quad$ Yes & $\mathbf{2 . 1 9}$ & $\mathbf{1 . 3 8 - 3 . 4 8}$ & $\mathbf{0 . 0 0 0 8}$ \\
\hline Lymphadenectomy & & & \\
$\quad$ No & 1.0 & - & - \\
$\quad$ Yes & 1.24 & $0.70-2.18$ & 0.46 \\
\hline
\end{tabular}

